\title{
O discurso sobre futebol e violência em Minas Gerais
}

\author{
Luciane Corrêa Ferreira * \\ Pedro Henrique Sousa da Silva**
}

\begin{abstract}
Resumo
Este artigo apresenta a linguagem metafórica, assim como metonímica, que surgiu em interações discursivas entre os participantes, quando conversaram sobre a convivência com a violência no futebol em Minas Gerais. Utilizamos uma abordagem da metáfora à luz da dinâmica do discurso que sustenta que as metáforas utilizadas pelas pessoas na fala refletem suas emoções, valores e opiniões. A análise foi centrada em dados coletados a partir da discussão em um grupo focal em Belo Horizonte, Minas Gerais. Nossa pergunta de pesquisa foi: de que maneira os participantes usam linguagem figurada quando falam sobre violência no futebol? Adotamos a análise do discurso à luz das metáforas (CAMERON et al., 2009), que nos permite refletir sobre a maneira como os brasileiros enfrentam situações de violência urbana e sobre a linguagem figurada que eles usam para conceitualizar a violência.
\end{abstract}

Palavras-chave: Violência urbana. Futebol. Linguagem figurada. Metáfora.

\section{Futebol e metáfora: motivações cognitivas}

Em um estudo realizado anteriormente, buscou-se investigar expressões metafóricas motivadas pelo domínio experiencial futebol na mídia brasileira. Objetivou-se discutir que domínios experienciais fonte vão mapear o domínioalvo futebol e vice-versa. Os resultados apontaram mapeamentos metafóricos que contemplaram os domínios experienciais fonte ARTE, GUERRA, RELIGIÃO, NEGÓCIO, EDIFÍCIO, utilizados para falar sobre o domínio-alvo FUTEBOL e o uso do esquema imagético de CONTÊINER (FERREIRA, 2011).

* Universidade Federal de Minas Gerais - UFMG. O projeto "Futebol, metáfora e violência urbana", que contou com uma bolsa PIBIC/PROBIC FAPEMIG em 2012, foi desenvolvido sob minha coordenação na Faculdade de Letras da UFMG, em colaboração com o projeto "Metáfora e a constante ameaça de violência urbana no Brasil", coordenado pela Profa. Ana Cristina Pelosi (UFC) no Ceará. O projeto guarda-chuva é coordenado pela Profa. Lynne Cameron da Open University, Milton Keynes, Reino Unido.

** Programa de Pós-Graduação em Linguística, Universidade Federal do Ceará. 
Estudos apontam que expressões metafóricas para descrever esportes e jogos frequentemente são motivadas pelos domínios experienciais ARTE, GUERRA, RELIGIÃO E VIOLÊNCIA (SIMÓ, 2008). Por exemplo, quando um repórter afirma que "a torcida não conseguia ver sangue durante o jogo", ${ }_{1}^{1}$ o domínio experiencial VIOLÊNCIA é ativado a fim de descrever a experiência abstrata de sofrimento envolvida quando os fãs assistem a um jogo de futebol. Simó distingue entre o domínio experiencial VIOLÊNCIA E GUERRA na conceitualização do jogo de xadrez, pois a autora argumenta que nem todas as expressões do domínio experiencial GUERRA, utilizadas para falar do esporte, são violentas, mas sim se referem à estratégia. $\mathrm{O}$ mesmo se aplica ao futebol, pois falamos de tática, ataque e defesa em futebol, e tais conceitos não estão necessariamente relacionados a atitudes violentas no campo.

Já que o futebol é considerado uma metáfora da sociedade e uma representação da vida social, a violência presente na sociedade brasileira tem se refletido também nos campos. O futebol - e os esportes em geral - são frequentemente descritos na Sociologia como rituais de violência simbólica com um objetivo civilizatório (ELIAS, 1994) por desestimularem a violência direta. A manifestação dessa violência, uma corda bamba entre o real e o simbólico, seria sempre acionada por um estímulo externo, como a impunidade, o descaso das autoridades e de políticas públicas, assim como por uma estreita relação com outras questões referentes à agressividade direta, como tráfico de drogas, xenofobia e racismo, ou indireta, como pobreza e exclusão social.

Portanto, o futebol não é violento, embora historicamente esteja associado a rituais de guerra e isso se reflita na linguagem utilizada para falar de e descrever o futebol, em que encontramos termos empregados no domínio experiencial GUERRA, como 'tática', 'ataque', 'defesa', entre outros. Os exemplos de violência no futebol que chamam mais atenção acontecem fora de campo e estão relacionados à atuação das torcidas organizadas no Brasil e ao fenômeno do hooliganismo na Europa. Embora um índice de violência de 5\% (MURAD, 2007, p. 21) no futebol brasileiro seja considerado problemático, a mídia sensacionalista faz com que a sensação de insegurança com relação à ida do espectador brasileiro aos estádios de futebol aumente. Tal insegurança também se reflete no discurso dos participantes do presente estudo. 


\section{Futebol e a metáfora discursiva}

Cameron (2003) sugere que, para se compreender a metáfora, é necessário entendê-la no seu uso dialógico como parte integrante do uso da língua, como propõe Bakhtin. A língua é aqui entendida como sistema dinâmico complexo. Assim, nas interações, o fluxo discursivo ocorre como um processo de "pensamento e fala", em que o uso de hifens na expressão sinaliza a estreita relação entre pensamento e linguagem. "Pensamento e fala" é um processo dinâmico e dialógico que exige a coconstrução situada por parte dos participantes da palavra do outro e a sua adaptação, a partir dessa compreensão, na proporção que intenções e emoções evoluem no fluxo do discurso. Dessa forma, cognição e linguagem seriam indissociáveis. As metáforas que emergem no discurso fazem parte de um processo dinâmico em constante mudança, motivado por fatores cognitivos, contextualmente e socioculturalmente situados, assim como fatores linguísticos. Objetivamos, assim, partindo do discurso produzido por vítimas diretas ou indiretas de violência no futebol em uma discussão com um grupo focal, verificar a emergência e constituição de expressões figuradas para conceitualizar a violência no futebol.

O método de análise do discurso à luz das metáforas trabalha com linguagem metafórica, especificamente, com veículos metafóricos (CAMERON, 2010) emergentes no discurso. Após a transcrição das gravações com auxílio do software Atlas.ti, as metáforas linguísticas são identificadas e codificadas. Em seguida, padrões de sistematicidade são identificados e examinados. Estudos realizados anteriormente apontaram para o fato de que as metáforas utilizadas pelos falantes revelam informações úteis sobre suas ideias, atitudes e valores. Por exemplo, o estudo de Cameron (2003) apontou que as metáforas utilizadas em interações em sala de aula revelam atitudes e expectativas de alunos frente ao processo de aprendizagem e possibilitam aos alunos outras maneiras de falar sobre os conteúdos aprendidos. Busca-se identificar metáforas sistemáticas no discurso que são como um fio encadeador na interação, sendo utilizadas e retomadas várias vezes pelos participantes do grupo focal. A metáfora sistemática configura-se como uma estabilização temporária no discurso e aparecerá nas análises em itálico.

Cameron mostrou como metáforas em conversas de reconciliação desvelam ideias-chave e mudam as atitudes dos participantes, conforme o processo de 
reconciliação evolui por meio de deslocamentos metafóricos, i.e., deslocamento do veículo (vehicle re-deployment), desenvolvimento do veículo e literalização do veículo. (CAMERON, 2008, p.61)

$\mathrm{O}$ discurso metafórico e o não metafórico se interconectam na concretização de objetivos discursivos, ao passo que as metáforas mudam na fala dos próprios participantes e entre participantes nas interações. Cada instanciação metafórica está fortemente encaixada no seu contexto discursivo imediato. À medida que se identificam, no fluxo da conversa, padrões no uso de metáforas, identificam-se os tópicos discursivos e, a partir daí, tem-se subsídios para a identificação das metáforas sistemáticas no discurso. $\mathrm{O}$ processo de listagem e separação das metáforas destaca o papel do contexto.

Este estudo foi desenvolvido em colaboração com o projeto "Metáfora e a constante ameaça de violência urbana no Brasil", coordenado pela Profa. Ana Cristina Pelosi em Fortaleza, Ceará, e do qual participam ainda professores da UCS e da UFMG. O projeto guarda-chuva é coordenado pela Profa. Lynne Cameron, da Open University, Milton Keynes, Reino Unido, e investiga como a linguagem figurada é empregada na interação para se falar de atos terroristas, sendo também objetivo do projeto comparar os dados sobre terrorismo com os dados sobre violência urbana no Brasil. No presente estudo, investigamos como participantes de um grupo focal falam sobre sua experiência com violência no futebol e seus sentimentos quanto ao tema como pessoas que vivenciam o futebol em Minas Gerais como torcedores de clubes mineiros. Silva (2013) investiga a violência no futebol do Ceará utilizando a mesma metodologia e com o mesmo objetivo, em que torcedores dos dois maiores clubes cearenses, Fortaleza e Ceará, participam de uma discussão em grupo focal. Há muitos paralelos entre os resultados dos dois estudos com torcedores de Minas Gerais e do Ceará.

$\mathrm{O}$ risco de violência urbana no Brasil é contínuo. Infelizmente tais riscos também se referem à violência no esporte. Cameron fala em "estórias circulantes" (circulating stories), que são eventos significativos que se transformam em estórias compartilhadas, e.g. o caso dos torcedores do Corinthians na Bolívia e o caso do torcedor do Cruzeiro morto por membros da Galoucura na região central de Belo Horizonte.

Em um estudo anterior com grupo focal, buscamos mostrar como o nome da torcida de um clube de futebol da capital mineira é mencionado por uma participante com um uso metonímico em uma interação em que os participantes relatam a sua 
experiência com violência urbana na cidade de Belo Horizonte. Veja no excerto acima como a participante Patrícia utiliza uma metonímia sistemática que veicula a imagem de um CONTÊINER (DENTRO/FORA) para referir a sensação de proteção por pertencer a um grupo, i.e., o sentimento de estar DENTRO, no caso dentro do grupo da torcida da Galoucura:

Patrícia: Teve uma vez que o cara tentou me assaltar, aí eu virei pra ele

$<$. qual é rapaz, aqui é galoucura

..cê vai mexer comigo, cê é doido?> [riso]

..aí ele saiu correndo, velho

saiu correndo de mim!

..Ele ficou com o maior medo

Bruno: ..Nó e eu passo mesmo

..não tô nem $\mathrm{f}$

..morrer de graça não

Patrícia: ..Eu já tô muito experiente em assalto

..já fui assaltada sete vezes

..da última eu falei

..da última eu fui esperta, meu filho, agora

agora eu sei que eu sou da galoucura [risos]

agora ninguém me assalta mais não.

(FERREIRA, 2012, p.174-175)

Na fala de Patrícia, Galoucura funciona como uma metonímia NOME pela AÇÃO, em que o nome Galoucura é automaticamente identificado com as ações violentas perpetradas por membros da torcida Galoucura. Ao proferir aqui é Galoucura, Patrícia aciona intencionalmente a inferência de que, se o agente de violência causar algum dano a ela, estará agindo contra a torcida, estabelecendo uma relação metonímica de PARTE-TODO. Ao falar "agora eu sei que eu sou da Galoucura", Patrícia também aciona a possível inferência de que inventou que é membro da Galoucura para motivar o sentimento de medo no seu interlocutor, o ladrão que ia assaltá-la. O submodelo com propriedades comuns que reúne semelhanças de família para configurar a categoria VIOLÊNCIA é o que congrega as propriedades AGENTE PERCEPTÍVEL, AÇÃO DIRETA, EMPREGO DA FORÇA FÍSICA e DANO MATERIAL (FELTES, 2007, p. 263), enfim algumas propriedades relacionadas com atividades com as quais a imagem da torcida Galoucura está relacionada. 


\section{Metodologia}

Este é um estudo de natureza qualitativa. Seguimos os procedimentos metodológicos descritos em Cameron et al. (2009). Onze participantes, estudantes de graduação na Universidade Federal de Minas Gerais (UFMG), participaram da coleta de dados em um grupo focal em outubro de 2012. A fim de promover a interação entre os participantes do grupo focal, um membro do grupo de pesquisa atuou como moderador da discussão. Foram adotados pseudônimos na transcrição, a fim de preservar a identidade dos participantes.

Os dados foram coletados por meio de entrevistas semiestruturadas. Procedeuse a uma análise do discurso guiada por metáforas (CAMERON et al., 2009), tendo os dados sido transcritos (13.880 palavras) com o apoio do software Atlas.ti, de análise qualitativa. Os dados foram posteriormente codificados em metáforas, metonímias, tópicos discursivos e cenários. Metáforas individuais foram reunidas em grupos de metáforas para se identificar padrões sistemáticos. Em primeiro lugar, identificaram-se os tópicos discursivos - TDs -, por exemplo, tópicos como 'pessoas', 'violência', 'mídia', 'autoridades', 'local', cf. Cameron (2010). A identificação dos TDs nos auxiliou a localizar os veículos metafóricos. Então, os veículos metafóricos depois foram identificados e agrupados. A identificação dos veículos metafóricos deu-se cf. uma versão adaptada do PIM ou MIP (Metaphor Identification Procedure), adotado pelo Grupo Pragglejaz (2007), que considera metafórico qualquer uso incongruente ou diferente de um termo que difere do seu significado mais concreto. Veículos metafóricos e metonímias foram identificados e codificados. Por exemplo, palavras ou expressões referentes à 'mídia' foram agrupadas, expressões relativas a 'localização' usadas com valor metonímico foram agrupadas, por exemplo 'estádio' e 'rua'.

O método de análise do discurso à luz das metáforas (CAMERON et al., 2009) se move constantemente por vários níveis que são o micronível de uma dada metáfora, os níveis intermediários de episódios de fala e veículos metafóricos, o macronível da conversação como um todo, finalmente tudo se insere dentro de um nível sociocultural mais amplo. A análise não é indutiva, de baixo para cima (bottom-up), baseada numa abordagem que ignora a possibilidade da existência de metáforas conceituais; nem dedutiva, de cima para baixo (top-down), partindo da premissa de que cada instância de metáfora na interação seria uma expressão 
linguística licenciada por metáforas conceituais. Trata-se de um processo interativo e recursivo que vai dos dados resultantes da interação no grupo focal ao contexto social maior (MACEDO, 2010). Adotaram-se os seguintes procedimentos metodológicos na análise dos dados:

1. adaptação do questionário de Cameron (2006), traduzido pelos membros do Grupo de Pesquisa GELP $2 /$ COLIN, da Universidade Federal do Ceará, para investigar violência urbana no Brasil, com o objetivo específico de abordar no grupo focal a violência no futebol (FERREIRA, 2011);

2. coleta de dados com um grupo focal ${ }^{3}$ com onze participantes em outubro de 2012;

3. transcrição dos dados coletados com o auxílio do software Atlas. ti;

4. análise dos dados.

Trabalhamos com corpora oriundos da gravação e filmagem de um grupo focal, buscando identificar e analisar metáforas recorrentes em seus discursos para sentimentos de agressividade e/ou outras noções referentes a situações de violência experimentadas por adultos, vítimas diretas ou indiretas de violência urbana. Os informantes foram selecionados entre frequentadores de cursos acadêmicos em nível de graduação da Universidade Federal de Minas Gerais, na faixa etária de 18 a 40 anos. Onze pessoas participaram da pesquisa, sendo sete mulheres e quatro homens. Os nomes dos participantes foram modificados para pseudônimos, a fim de preservar o sigilo de sua identidade. A participação de cada informante foi voluntária e todos os participantes assinaram um Termo de Consentimento Livre e Esclarecido concordando em participar da pesquisa. ${ }^{4}$ A duração máxima do período de discussão em grupo foi de 80 minutos. Treze perguntas foram lançadas uma a uma para o grupo conforme procedimentos previamente adotados quando da coleta de dados para o projeto sobre metáfora e violência urbana em Minas Gerais (FERREIRA, 2012). As discussões foram filmadas e transcritas para análise. Identificamos nas interações os tópicos discursivos, narrativas, veículos metafóricos, metáforas e metonímias sistemáticas referentes à conceitualização

2 Grupo de Estudos da Metáfora na Linguagem e no Pensamento.

3 Houve duas coletas de dados anteriores em 2012, uma anterior (9.035 palavras), com oito participantes, também sobre violência no futebol.

4 Projeto aprovado pelo Comitê de Ética em Pesquisa - COEP - da UFMG em 2011. 
da violência no futebol, nosso objeto de estudo. Os dados foram codificados para identificar as metáforas e metonímias, assim como narrativas pessoais e cenários. Metáforas individuais foram agrupadas para se encontrarem padrões sistemáticos de metáforas. Também foi realizada uma análise das metáforas conceituais (LAKOFF; JOHNSON, 1980) e dos esquemas imagéticos, por exemplo: FONTE-CAMINHO-META e CONTENIMENTO (JOHNSON, 1987) observados nos dados, i.e., os elementos cognitivos identificados nos dados, o que nos auxiliou a entender as motivações cognitivas nas interações discursivas.

Resultados apontam para os seguintes tópicos discursivos nas interações do grupo focal analisado (FERREIRA, 2013):

\author{
•Emoções \\ -Estrutura do futebol no Brasil \\ - Fazer parte de um grupo \\ -Futebol no exterior \\ -Mídia \\ -Mudança \\ -Política \\ -Educação \\ -Atitudes dos jogadores \\ -Autoridades \\ - Comparação com outros esportes \\ - Grupos afetados pela violência \\ -Respeito \\ -Violência
}

Fig. 1 - Tópicos Discursivos (FERREIRA, 2013) 


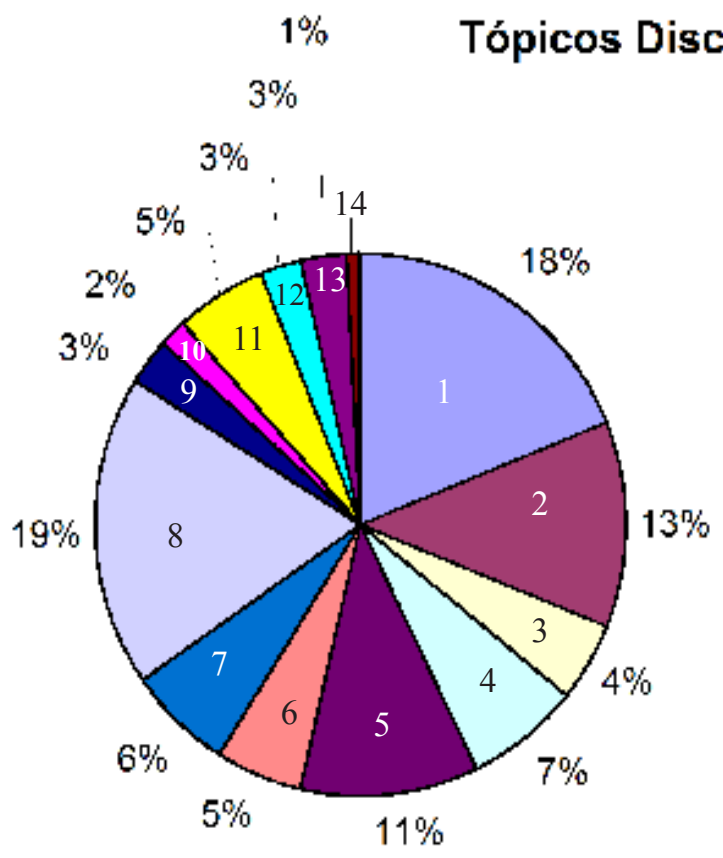

1 Emoções

$2 \square$ Estrutura do futebol no Brasil

$3 \square$ Fazer parte de um grupo

4 ㄷ

$5 \square$ Mídia

$6 \square$ Mudança

$7 \square$ Política

8 口Violência

9 Respeito

$10 \square$ Educação

$11 \square$ Atitudes dos jogadores

$12 \square$ Autoridades

$13 \square$ Comparação com outros esportes

$14 \square$ Grupos afetados pela violência 
Veja-se na sequência como esses Tópicos Discursivos (TDs) aparecem nos dados de uma maneira recorrente, motivando metáforas discursivas:

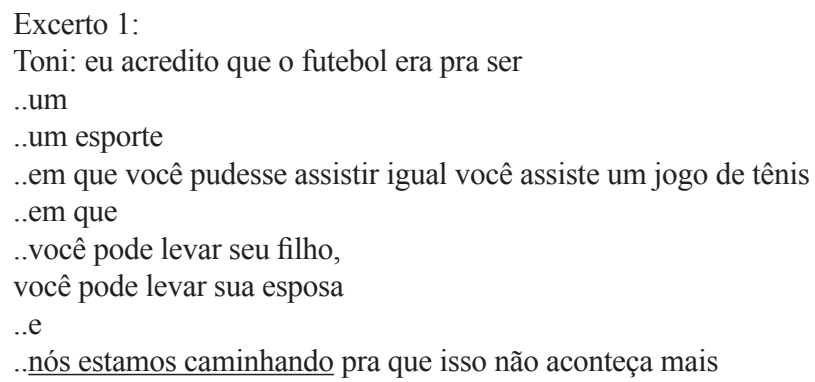

No excerto 1, Toni veicula o Tópico Discursivo 'comparação com outros esportes' do quadro acima e vai utilizar um esquema imagético FONTE-CAMINHO-META para descrever a trajetória para onde a violência está nos conduzindo. Nesse caso, a violência está sendo conceitualizada nos dados como um CAMINHO, com início, que percorre uma trajetória e cujo objetivo é acabar com a liberdade do cidadão de se deslocar livremente. No excerto a seguir, foi constatado um uso metonímico.

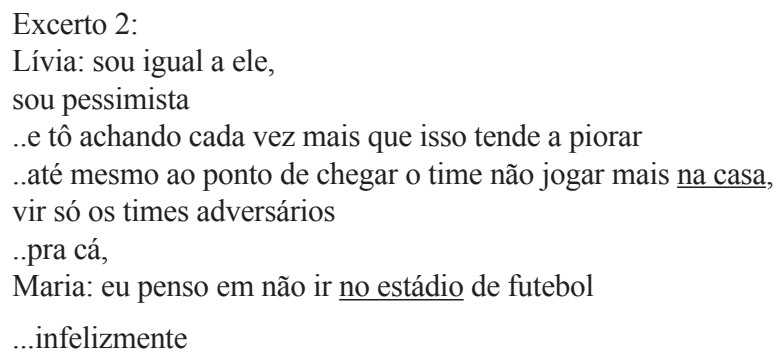

No excerto 2, por meio do Tópico Discursivo 'localização’, identificamos o veículo metonímico 'casa', que se repete nos dados sobre violência no futebol, já que 'jogar na casa' significa jogar 'no estádio do seu time', e é muito importante para o time por poder jogar com o apoio da sua torcida, i.e., sentir-se seguro. Coincidentemente, 'casa' significa, metonimicamente, 'segurança' nos dados sobre violência urbana no Brasil (FELTES; PELOSI; FERREIRA, 2012), e não poder jogar 'na casa' é descrito pela torcedora como um motivo de grande tristeza, pois jogar e vencer 'na casa', i.e., 
na sua sede, no seu estádio, está associado com um grande valor simbólico para a torcida. No excerto 3, a participante revela seu temor em ir ao 'estádio', trata-se do temor do que pode vir a acontecer no que vem sendo denominado na mídia como 'o caminho do torcedor'. Nesses dois casos, foi detectado nos dados o que Cameron (2010) denominou de 'metáforas da paisagem social', i.e., um conjunto de metáforas espaciais utilizadas para conceitualizar as relações entre a sociedade e vários grupos sociais, principalmente metáforas que indicam 'PAISAGEM', 'MOVIMENTO' e 'CONTÊINER' (p. 606). Tal cenário, acessado por meio de tais metáforas, possibilita o 'pensar e falar', à medida que as pessoas podem ajustar as suas concepções de como grupos sociais interagem. Segundo Cameron, isso está relacionado ao fato de diferentes grupos sociais geralmente ocuparem locais diferentes nas cidades. No caso dos dados de Cameron, as comunidades de muçulmanos vivem restritas a uma determinada área de cidades industriais na Inglaterra e constituem uma comunidade homogênea. No caso dos dados do Brasil sobre metáfora e violência urbana, também se verificam referências a grupos sociais restritos a uma determinada área da cidade, como é o caso das favelas e aglomerados nas grandes cidades brasileiras, lugares que são referidos nos dados sobre violência urbana por meio do esquema imagético do 'CONTÊINER', em que temos as dicotomias 'rua'/‘casa' e 'rua'/'estádio', sendo que os lugares fechados significam, metonimicamente, 'lugar seguro', e os lugares abertos onde, como fala a participante Clara, a seguir, ocorre a 'batalha' significam ‘perigo’ para os torcedores. A seguir, veja como o 'medo', outro Tópico Discursivo que aparece nos dados sobre violência urbana no Brasil em geral, é conceitualizado pela participante Clara.

Clara: O campo de batalha vai mudar, né.

Ricardo: [Uhum, vai sair da rua e],

Clara: ..naquele episódio que teve ali na frente do Chevrolet Hall, ... Ricardo: os caras desceram pra brigar.. e um ${ }^{5}$ morreu.

Excerto 5:

Ricardo: ..no Mineirão, dentro do estádio a segurança é muito efetiva, dá muito certo.

5 Aqui está implícita a palavra 'torcedor', pois um jovem torcedor do Cruzeiro foi assassinado a pauladas. A imagem do seu corpo estendido no meio da rua apareceu na mídia televisiva em todo o Brasil. 
Veja, no excerto a seguir, como a participante Maria lamenta o fato de não poder 'vestir a camisa' do time. "Vestir a camisa' pode ser interpretado literalmente, mas também tem um significado metafórico à medida que 'vestir a camisa' também significa para o torcedor a identificação com o time de futebol para o qual torce. Inclusive, a expressão metafórica 'vestir a camisa' é utilizada em outros contextos, como, por exemplo, o empresarial, quando queremos dizer que uma pessoa se identifica totalmente com uma proposta ou uma política. Por exemplo, na frase 'ela vestiu a camisa da empresa', a expressão 'vestir a camisa' significa que a funcionária é muito motivada e vai fazer todo o possível para beneficiar o seu empregador.

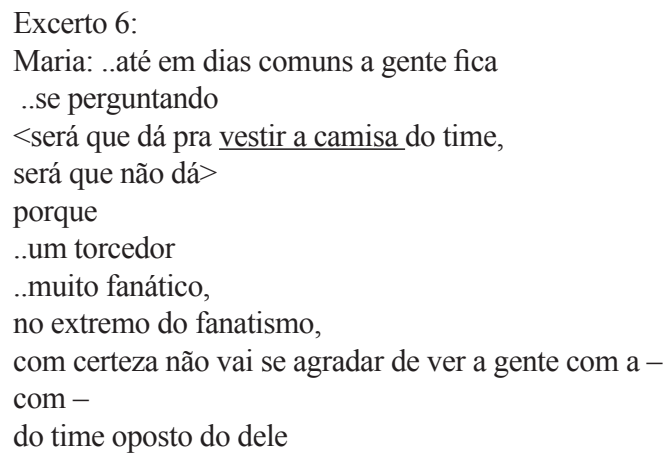

Nos excertos a seguir, resultantes da investigação de Silva (2013) sobre a experiência dos torcedores de Fortaleza sobre a sua ida ao estádio, verificamos o mesmo fenômeno: a palavra 'camisa' é utilizada primeiro literalmente (1.33) e depois metonimicamente (1.39) ao longo da fala do torcedor para referir emoções como medo e insegurança quando o torcedor fala na sua ida ao estádio para assitir a um jogo.

29.Carlos Eu sou uma pessoa que sou fanática pelo Ceará e tudo, eu vou pro estádio e eu gosto de ir no caminho do torcedor 30.Alex $<\mathrm{XX}>\mathrm{O}$ cara ainda vai com medo ainda, vai com medo -

31. Carlos Não sei o que vai acontecer 32. Alex $<X X>$ A pessoa vai assim, não sabe se volta, não sabe se volta.

33. Carlos Eu gosto de usar a camisa34. Alex Infelizmente tá assim.

35. Carlos Eu gosto de usar a camisa da torcida organizada, eu gosto 
36. Carlos Mas só que eu não me misturo com eles.

37. Antônio Dois

38. Carlos Mas se alguém me pegar vestido com aquela camisa na saída do estádio, na $\langle\mathrm{XX}>$, sei lá.

39. Alex Aí o pessoal apanha por causa que tá usando a camisa, mesmo não sendo do -

Veja como, na linha 39, 'camisa' significa metonimicamente o sentimento de pertencimento do torcedor a um determinado clube de futebol, no caso o Ceará. Contudo, veja como na linha 36 , o participante nega o seu pertencimento à torcida organizada, chegando mesmo a afirmar que "não se mistura" com eles, em função da imagem de torcida violenta do time.

No excerto acima, na linha 29, Carlos usa o veículo metafórico "gosto de ir no caminho do torcedor", metaforizando o deslocamento espacial do torcedor e promovendo, logo em seguida, a retomada da discussão na qual o tópico 'medo' se inscreve. A retomada desse tópico pode ser observada na linha 30, em que o informante Alex usa um veículo metonímico "O cara vai com medo ainda", conectando-o ao tópico discursivo 'medo'.

$\mathrm{Na}$ linha 38, Carlos retoma o veículo metonímico 'camisa', usado em linhas anteriores, associando-o aos tópicos medo e insegurança: “...se alguém me pegar usando aquela camisa na saída do estádio..” Logo em seguida, na linha 39, Alex, por sua vez, também faz uso desse veículo metonímico, associando-o aos tópicos medo e insegurança: “...Aí o pessoal apanha por causa que tá usando a camisa, mesmo não sendo do - ...”. Nesse sentido, os veículos metafóricos e os metonímicos vão se readaptando recorrentemente no fluxo da interação discursiva, formando redes de metáforas e de metonímias semanticamente semelhantes entre si, conectadas aos também recorrentes tópicos 'medo', 'insegurança' e, sobretudo, ao macrotópico em debate, ou seja, à 'violência no futebol'. Tendo em vista essas ocorrências, o processamento da conceitualização da violência no futebol a partir da interação discursiva em análise estabilizou-se temporariamente como a seguinte metáfora sistemática proposta: VIOLÊNCIA NO FUTEBOL É UM AGENTE QUE LIMITA O DESLOCAMENTO DO TORCEDOR.

Verificou-se que tanto os participantes do grupo focal em Belo Horizonte como os participantes do grupo focal em Fortaleza (SILVA, 2013) conceitualizaram a violência no futebol como um $A$ GENTE QUE LIMITA O DESLOCAMENTO DO TORCEDOR. 


\title{
Considerações finais
}

Vimos, no presente artigo, como metáforas e metonímias sistemáticas são utilizadas pelos participantes de um grupo focal, a fim de discutir a sua experiência e expressar suas emoções como vítimas diretas e indiretas de violência no futebol. Um participante do grupo focal recorre à metonímia sistemática camisa para descrever como as pessoas procuram disfarçar a sua condição de torcedor para evitar despertar a atenção do agente da violência.

Vimos, portanto, como metáforas e metonímias sistemáticas são utilizadas numa interação por participantes de um grupo focal ao discutir sobre sua experiência e as suas emoções com relação à violência no futebol vivenciada na cidade de Belo Horizonte. Constatamos, como observou Cameron (2010), que metáforas e metonímias sistemáticas não são exclusivas de um único evento discursivo, como pudemos verificar nos dados do grupo focal do presente estudo, sobre violência no futebol em Belo Horizonte e nos dados de Silva (2013) sobre violência no futebol em Fortaleza, em que a metonímia sistemática 'camisa' se repete na fala dos participantes nas duas discussões.

\section{The discourse about football and violence in Minas Gerais}

\begin{abstract}
This paper presents metaphorical as well as metonymical language which emerged in discursive interactions among participants when they talked about violence and soccer in Minas Gerais, Brazil. We take a discourse dynamics approach to metaphor that holds that the metaphors people use in talk reflect their emotions, values and understandings. The analysis is focussed on data gathered from the discourse produced by a focus group discussion in Belo Horizonte, Minas Gerais. Our research question is how do participants use figurative language when they talk about violence and soccer? We adopted metaphor-led discourse analysis (CAMERON et al., 2009), which enables us to reflect on the way how Brazilians face situations of violence related to soccer and the figurative language they use in order to conceptualize violence.
\end{abstract}

Keywords: Urban Violence. Football. Figurative language. Metaphor. 
Referências

CAMERON, Lynne. Metaphors in educational discourse. London: Continuum, 2003.

CAMERON, Lynne. Responding to the risk of terrorism: the contribution of metaphor. Delta, v. 26, n. spe, p. 587-614, 2010. Disponível em: <http://www. scielo.br/pdf/delta/v26nspe/v26nspe10.pdf $>$.

CAMERON, Lynne. Metaphor shifting in the dynamics of talk. In: ZANOTTO, Mara Sophia; CAMERON, Lynne; CAVALCANTI, Marilda C. (Org.). Confronting metaphor in use: an applied linguistic approach. Amsterdam: John Benjamins Publishing Company, 2008. p. 45-62.

CAMERON, Lynne; MASLEN, Robert. Metaphor analysis: research practice in applied linguistics, social sciences and the humanities. London, UK: Equinox Publishing Ltd, 2010.

CAMERON, Lynne; MASLEN, Robert; TODD, Zazie; MAULE, John; STRATTON, Peter; STANLEY, Neil. The Discourse Dynamics Approach to Metaphor and Metaphor-led Discourse Analysis. Metaphor and Symbol, v. 24, n. 2, p. 63-89, 2009.

ELIAS, Norbert. O processo civilizador. Rio de janeiro: Zahar, 1994. v. 1.

FELTES, Heloísa Pedroso de Moraes. Semântica cognitiva: ilhas, pontes e teias. Porto Alegre: Edipucrs, 2007.

FERREIRA, Luciane Corrêa. Social status, metaphor and discourse about urban violence in Belo Horizonte, Brazil. No prelo.

FERREIRA, Luciane Corrêa. O discurso sobre futebol e violência em Minas Gerais. In: CONFERÊNCIA LINGUÍSTICA E COGNIÇÃO, 5., 2013, Santa Cruz do Sul. Caderno de resumos: Simpósio Metáfora e Violência. Santa Cruz do Sul: UNISC, 2013. Comunicação oral.

FERREIRA, Luciane Corrêa. A conceitualização de violência e futebol. Antares, v. 4, n. 7, p. 166-177, 2012.

FERREIRA, Luciane Corrêa. Futebol e metáfora na mídia. In: CONGRESSO LATINO-AMERICANO DE ESTUDOS DO DISCURSO, 9., 2011, Belo Horizonte. Anais... Belo Horizonte: FALE, UFMG, 2011. 1 CD-ROM. 
JOHNSON, Mark. The body in the mind. Chicago: Chigago University Press, 1987.

MACEDO, Ana Cristina Pelosi Silva de. Metáfora, cognição e cultura: um estudo sobre conceitualizações de violência urbana em Fortaleza-Ceará-Brasil. Projeto PIBIC, PPGL, UFC, Fortaleza, 2010.

MURAD, Mauricio. Violência e futebol. Rio de Janeiro: Fundação Getúlio Vargas, 2007.

PRAGGLEJAZ GROUP. MIP: A method for identifying metaphorically-used words in discourse. Metaphor and symbol, v. 22, n. 1, p. 1-39, 2007.

SILVA, Pedro Henrique Sousa da. Emergência de metáforas sistemáticas na interação discursiva entre torcedores vítimas da violência no futebol. Ensaio de Qualificação. Dissertação em andamento. Programa de Pós-Graduação em Linguística, Universidade Federal do Ceará, Fortaleza, 2013.

SIMÓ, Judit. Chess Metaphors in American English and Hungarian. Metaphor and symbol, v. 24, n. 1, p. 42-59, 2008. 
Dossiê

Metáfora e cognição 
